\title{
Barriers to physical activity in adolescents: A systematic review
}

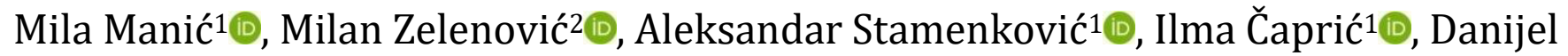 \\ Božić(i)2
}

${ }^{1}$ Faculty of Sport and Physical Education, University of Nis, Serbia. ${ }^{2}$ Faculty of Physical Education and Sport, University of East Sarajevo, Bosnia and Herzegovina.

\begin{abstract}
The aim of the research was to determine, based on a systematic review of published studies that dealt with barriers to physical activity in adolescents, which are the most common barriers that stop adolescents from engaging in physical activity. Within the research original scientific studies are included, the ones that had male and female adolescents as a sample of respondents, studies related to the analysis of barriers that occur in adolescents, in which assessments were made on the basis of a questionnaire related to barriers. The research included studies from January 1, 2003 to July 2020. The final analysis, based on the set criteria, included 11 studies that were processed and presented. Most studies have shown that more internal barriers than external ones occur in girls comparing to boys, while external barriers are more common causes of not engaging in physical activity in boys. The three most common barriers among boys were: lack of company, lack of time and school obligations. Among girls, the most commonly reported barrier was "I'd rather do some other activities" and reporting a lack of time. The significance of this research is that it provides information on barriers in respondents who are adolescents, ie the reasons why their physical activity is reduced or they do not engage in physical activity at all. The significance of this research is that it provides information on barriers in respondents who are adolescents, ie the reasons why their physical activity is reduced or they do not engage in physical activity at all.
\end{abstract}

Keywords. Activity, adolescents, barriers, perceived, students.

\section{Introduction}

Regular physical activity is very important for health promotion, for the prevention of musculoskeletal disorders, for reducing the risk of developing coronary heart disease, hypertension, diabetes, osteoporosis, obesity and colon cancer (Kann et al., 2000; Trost et al., 2002). Regarding the fact that an insufficiently active person is someone who does not engage in physical activity according to the recommendations of the World Health Organization (WHO, 2010), 8.2\% of boys and $16.3 \%$ of girls aged 5 to 14 belong to this group. The level of physical activity tends to decrease with age, so that $21.4 \%$ of boys and $49.5 \%$ of girls aged 15 to 24 are insufficiently active (Sistema Nacional de Salud).
According to one of the medical glossaries, adolescence is the period between the beginning of puberty and adulthood. It usually begins between the ages of 11 and 13 with the appearance of secondary sexual characteristics and lasts through the teenage years until the age of 18-20, when it completes development into an adult.Intense physical, psychological, emotional, and personal changes occur during this period (UNFPA, 2006). Adolescence is a key time period for an individual's future as well as many behaviors and habits that become part of one's lifestyle that is established at this stage (Eccles et al., 1993). Adolescence is usually considered to be the healthiest period of life, in which the peak of strength, speed, fitness, and many cognitive abilities is reached

\footnotetext{
凶M. Zelenović, e-mail: milanzeleni13@gmail.com

Received: July 29, 2020 - Accepted: February 10, 2021 - Published: March 30, 2021

To Cite: Manić, M., Zelenović, M., Stamenković, A., Čaprić, I., Božić, D. (2021). Barriers to physical activity in adolescents: A systematic review. Turk J Kinesiol, 7(1), 22-30. DOI: 10.31459/turkjkin.840536
} 
(Kleinert, 2007). The decline in physical activity was evident during the transition of young people to early maturity, with the largest decline in physical activity occurring during college enrollment (Kwan et al., 2012; Sigmundova et al., 2013). Younger adolescents with less physicalcapability have a higher obesity rate than adults (Kvaavik et al., 2009). There are many factors that affect participation in physical activities. This includes demographic variables, knowledge, attitudes, and beliefs about physical activity. There are two cognitive variables, which are taken into account when assessing the level of physical activity, and they are: perceived advantages and perceived obstacles. Perceived benefits can positively affect physical activity while barriers can negatively affect participation in activities (Buckworth \& Dishman, 1999).

These barriers are classified in different ways. Many studies conducted in some countries have assessed the benefits and barriers to engaging in physical activity among young people (Kennet et al., 1999; Grubbs \& Carter, 2002; Cheng et al., 2003; Vinters et al., 2003; Giurcsik et al., 2004; Brown, 2005). Barriers that occur in young people including the high cost of equipment (Hesketh et al., 2005; Kubik et al., 2005), low accessibility or availability of spaces and facilities such as playgrounds (Allison et al., 2005; Cohen et al., 2006) and the unsafe location of facilities for physical activity (Bauer et al., 2004; Gordon-Larsen et al., 2004; Cohen et al., 2006). Parents explained that one of the obstacles may be the problem of lack of time or motivation to exercise with their children (Gordon-Larsen et al., 2004; Harrison et al., 2005; Hesketh et al., 2005). The perception of barriers to with leisure timephysical activity has increased in developed countries and is associated.Therefore, engaging in physical activity competes with many leisure activities that are more attractive to adolescents (Escat, 2013; Sigmundová et al., 2013). Sedentary activities can also be an obstacle, as young people may prefer to engage in technological activities (TV, Internet, video games) rather than physical activity (Allison et al., 2005). Schools do not provide enough opportunities for physical activity (Kubik et al., 2005; Bauer et al., 2006; Hohepa et al., 2006), and insufficient funding for physical activity and low levels of adult supervision in secondary schools are associated with low levels of physical activities of students in schools. Physical appearance can also be an obstacle to physical activity in the adolescent population. Adolescents cited concerns about appearance during and after physical activity as an obstacle (Robbins et al., 2003). In adults, the usual barrier is lack of time or a large number of obligations (business obligations, household chores, especially for women). This example could provide an answer to the ranking of physical activity in an individual's life and how behavior will be in adulthood, and be an example to adolescents who will reproduce similar patterns of behavior in the future (Niñerola et al., 2006; Singh et al., 2008; Stankov et al., 2012). Socioeconomic status is also an obstacle to regular physical activity, as well as the acquisition of other healthy habits such as those related to diet (Rodenburg et al., 2005; Janssen et al., 2006; Gubbels et al., 2013).

According to a study on sports habits in Barcelona (2012-2013), the reason why schoolchildren and adolescents do not do exercises enough is lack of time (21.3\%), lack of money (15.9\%) and school obligations (15.8\%). A significant aspect is the fact that of those who do not play any sport, $73.7 \%$ have played a sport in previous years. Scientific evidence suggests that adolescents who engage in physical activity are in much better shape, such as improving their musculoskeletal system. The relationship between regular physical activity and different health conditions is such that physical activity improves body fat levels, improves aerobic capacity, increases skeletal muscle mass and improved body self-perception that has been identified in previous studies (Haugen et al., 2013; Ortega et al., 2013). Many studies have used schools as the primary environment with a combination of different strategies, including classroom education, changes in the environment, school meals, reduced use of television or computers, and parental involvement. The subgroup included middle school youth (Goh et al., 2009).

This systematic review includes studies that have analyzed the levels of physical activity and certain barriers that occur when engaging in physical activity that occur in adolescents. The benefits of regular physical activity are well presented. The reasons why individuals do not engage in physical activity are sufficiently complex and multiple, including personal determinants, as well as environmental determinants and other external factors. Systematic review work that deals with the analysis of any of these factors gives them the potential to better inform the benefits of engaging in physical activity and thus show a positive impact on the health of the individual. It is necessary to investigate the motives and challenges that adolescents face in trying to be active.

The aim of the research is to determine, based on a systematic review of published studies that have dealt with barriers to physical activity in adolescents, the 
most common barriers that prevent adolescents from engaging in physical activity.

\section{Methods}

\section{Search Strategy}

Review and analysis of studies were conducted in accordance with PRISMA (Preferred Reporting Items for Systematic Reviews and Meta-analyzes) guidelines (Moher et al., 2009). The research is with included studies from January 1, 2003 to July 2020. The databases searches were used: Google Scholar, PubMed, Web of Science, refseek and Research Gate. Databases were searched based on the following keywords: barriers, students, adolescents, perceived and activity. Reference lists from the undertaken studies were also reviewed to obtain more researches that studied this area. The search was exclusively for studies written in English and original scientific ones from available journals. In the first phase of the search, the relevance of the titles and abstracts of the identified works was checked. In the second phase of the search, the complete studies were taken over and considered for inclusion.

\section{Inclusion Criteria}

This research includes original scientific studies, for a sample of male and female adolescents who do not suffer from acute or chronic diseases, studies related to the analysis of barriers that occur in adolescents, in which assessments were performed, based on a questionnaire related to barriers. Additional criteria were that the paper contained transfer studies, and only studies in the last 20 years (after 2000) were considered. All studies that have appropriate ethical approval from the relevant committee and parental approval for underage subjects are included.

\section{Exclusion Criteria}

Criteria on the basis of which the studies were excluded from further analysis are papers written in other languages, inadequate sample of respondents (do not belong to the group of adolescents), papers in which the results are not adequately presented or the parameters needed for further analysis are missing. There was no exclusive criterion when it comes to the physical fitness of the respondents, as well as how long they play or do not play sport, there was no exclusive condition when it comes to the division of respondents into groups.

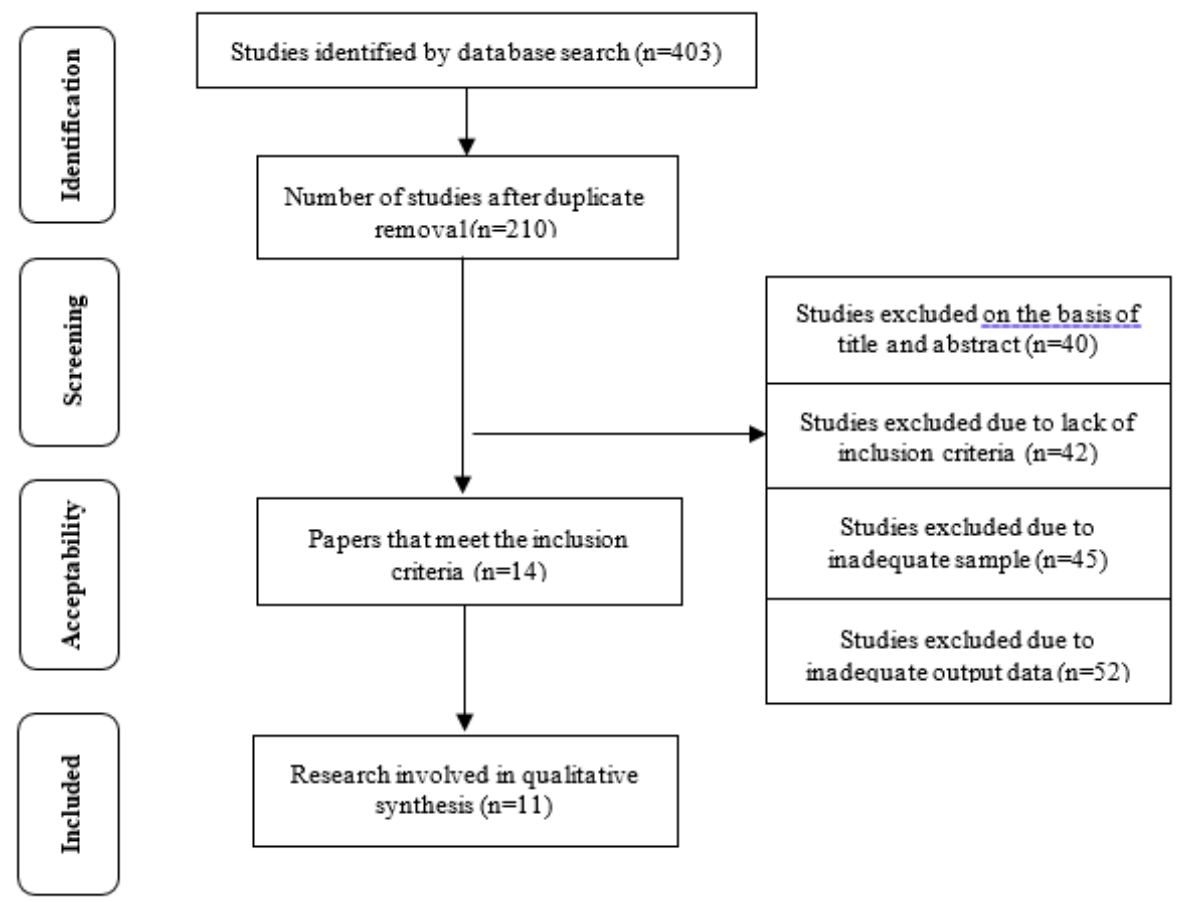

Figure 1. Diagram showing the identification, screening and selection of relevant studies in this systematic review. 


\section{Selection of Studies}

A search of electronic databases and scanning of reference lists of articles revealed 403 relevant studies (Figure 1). After removing the duplicates (210), 193 studies remained. Based on a review of titles and abstracts, 40 studies were rejected (after titles' analyses 17; and 23 after abstracts' analyses). The full text of the 153 remaining studies was taken into detailed analysis. Each study was read and selected based on the characteristics of the study, information about the respondents, the methods used, and the results of the studies. According to the inclusion criteria, 42 studies were excluded for some reason because they did not meet the inclusion criteria, while 11 studies that met the inclusion criteria were included in the systematic review.

The collected researches, used for this study is shown in Table 1. Each research is presented using the following parameters: research (first author and year of publication of the paper), sample of respondents (number of respondents (n), age and gender of respondents) (M, F), instruments, and outcomes (monitored variables).

\section{Results}

Available data on barriers to physical activity are shown in Table 1 . The total number of respondents was 6683 , because the studies were conducted on a large number of samples related to a specific population and the number varied from study to study. The target groups were adolescents, male and female, where the age of the respondents ranged from 8 to 20 . The barriers most commonly encountered in the studies were lack of motivation, lack of support, lack of energy, lack of time, inaccessibility to the facilities.

\section{Lack of Time}

The most important external barrier is the lack of time in the studies of Arzu et al. (2006), Fernández et al. (2016), Stanish et al. (2015) and Rosselli et al. (2020) with average scores of $\mathrm{M}=7.60, \mathrm{~F}=7.17$ and $\mathrm{M}=2.7, \mathrm{~F}$ $=3.3$ and $55 \%$ (Stanish et al., 2015) and $\mathrm{M}=2.0, \mathrm{~F}=3.4$. In a study by Butt et al. (2011), the results showed that the mean score was $\mathrm{M}=11.2, \mathrm{~F}=12.0$ on a scale of 420. Studies by Jodkowska et al. (2015) and Dias et al. (2015) showed that $31.7 \%$ and $43.7 \%$ of adolescents, respectively, consider lack of time as a barrier and
$50.5 \%$ and $48.8 \%$ of adolescents, respectively, while in the study by Youssef et al. (2013) slightly less 39.6\%.

\section{Lack of Support}

The lack of support was presented as the biggest barrier in the study by Dias et al. (2015), ( $M=58.7 \%$; F $=75.8 \%$ ). In the studies of Robbins et al. (2003) and Jodkowska et al. (2015), $46.8 \%$ and $45.7 \%$ of adolescents considered the lack of support a barrier, while significantly fewer adolescents $(36.8 \%)$ in the study of Jodkowska et al. (2015) while in the study of Youssef et al. al. (2013) as much as $71.5 \%$. A study by Stanish et al.(2015) found that only $6.7 \%$ of adolescents do not engage in physical activity due to lack of support.

\section{Lack of Motivation}

Lack of motivation as a barrier had an average score of 1.9 to 3.2, where girls graded higher compared to boys. The highest average score was 3.2 in the study by Rosselli et al. (2020), mean score is $2.68 ; 58.5 \%$ in a study by Robbins et al. (2003).

\section{Fear of Injury}

Stanish et al. (2015) found that 33\% of adolescents have a fear of injury, while in a study by Rosselli et al. (2020) the least barrier to physical activity was fear of injury $(\mathrm{M}=0.8 ; \mathrm{F}=0.6)$.

\section{Lack of Energy}

The most important internal barrier was the lack of energy in the studies of Arzu et al. (2006), where 4 out of 12 questions related to the lack of energy had a value over 3.0 in the study of Lovel et al. (2010) 2.63, in the study of Fernández et al. (2016) with an average score of 2.4, in the study by Youssef et al. (2013) with a score of 2.28, and in the study by Rosselli et al. (2020) $\mathrm{M}=$ $2.2, \mathrm{~F}=3.8$. A similar score in adolescents was obtained in the study by Fernández et al. (2016), 2.8 compared with adolescents with a score of 1.9. The same difference between adolescents occurred in a study by Jodkowska et al. (2015) ( $\mathrm{M}=35.9 \% ; \mathrm{F}=55.4 \%)$. 
Table 1

Outcomes for barriers to physical activity

\begin{tabular}{|c|c|c|c|c|c|c|c|c|c|c|c|c|}
\hline \multirow{2}{*}{ Study } & \multicolumn{2}{|c|}{ Sample characteristics } & \multirow{2}{*}{ Instruments } & \multicolumn{9}{|c|}{ Outcomes } \\
\hline & $n$ & Gender & & $L T$ & $L S$ & $L M$ & $F I$ & $L E$ & $I E F$ & $A D E$ & SO & $O A$ \\
\hline $\begin{array}{l}\text { Robbins et al., } \\
2003\end{array}$ & $\begin{array}{c}\mathrm{n}=77 \\
11-14 \text { years }\end{array}$ & $\mathrm{F}=77$ & 23-item questionnaire, (Likert scale 1 to 5) & $\mathrm{F}=2.59$ & $\mathrm{~F}=2.61$ & $\mathrm{~F}=2.68$ & & $\mathrm{~F}=2.51$ & & $\mathrm{~F}=2.80$ & $\mathrm{~F}=2.55$ & \\
\hline Arzu et al., 2006 & $\begin{array}{c}\mathrm{n}=303 \\
20.5 \text { years }\end{array}$ & $\begin{array}{l}M=81 \\
F=222\end{array}$ & $\begin{array}{l}\text { Questionnaire of } 12 \text { questions, (Likert's } \\
\text { Scale 1-5). } 2 \text { questions for each barrier }\end{array}$ & $\begin{array}{l}M=7.60 \\
F=7.17\end{array}$ & $\begin{array}{l}M=6.35 \\
F=5.92\end{array}$ & $\begin{array}{l}M=5.88 \\
F=4.93\end{array}$ & & $\begin{array}{l}M=7.00 \\
F=5.68\end{array}$ & $\begin{array}{l}M=4.75 \\
F=5.12\end{array}$ & $\begin{array}{l}\mathrm{M}=4.24 \\
\mathrm{~F}=3.56\end{array}$ & & \\
\hline $\begin{array}{l}\text { Sheraret al., } \\
2008\end{array}$ & $\begin{array}{c}\mathrm{n}=221 \\
8-16 \text { years }\end{array}$ & $\mathrm{F}=221$ & $\begin{array}{l}\text { Obstacle questionnaire for FA in the last } 7 \\
\text { days. }\end{array}$ & $\mathrm{F}=8.60 \%$ & $\mathrm{~F}=33.94 \%$ & $\begin{array}{c}\mathrm{F}=12.22 \\
\%\end{array}$ & $\mathrm{~F}=15.8 \%$ & & $\mathrm{~F}=8.14 \%$ & & $\mathrm{~F}=18.14 \%$ & $\mathrm{~F}=4.52 \%$ \\
\hline Lovel et al., 2010 & $\begin{array}{c}\mathrm{n}=200 \\
19.03 \text { years }\end{array}$ & $\mathrm{F}=200$ & 14-item questionnaire (Likert scale 1-4). & 2.12 & 2.06 & & & 2.63 & 2.08 & & & \\
\hline Butt et al., 2011 & $\begin{array}{c}\mathrm{n}=1163 \\
13-16 \text { years }\end{array}$ & $\begin{array}{l}\mathrm{M}=460 \\
\mathrm{~F}=703\end{array}$ & $\begin{array}{l}\text { 12-item questionnaire, } 4 \text { questions related to } \\
\text { lack of time (score } 4-20) ; 6 \text { issues related to } \\
\text { lack of energy (6-30); } 4 \text { questions related to } \\
\text { other activities (4-20). }\end{array}$ & $\begin{array}{l}\mathrm{M}=11.2 \\
\mathrm{~F}=12.0\end{array}$ & & & & $\begin{array}{l}\mathrm{M}=15.1 \\
\mathrm{~F}=16.2\end{array}$ & & & & $\begin{array}{l}\mathrm{M}=9.1 \\
\mathrm{~F}=9.5\end{array}$ \\
\hline $\begin{array}{l}\text { Youssef et al., } \\
2013\end{array}$ & $\mathrm{n}=439$ & $\begin{array}{l}\mathrm{M}=214 \\
\mathrm{~F}=225\end{array}$ & 12-Question Questionnaire (Ratings 1-5) & & $\begin{array}{l}\mathrm{M}=3.15 \\
\mathrm{~F}=3.18\end{array}$ & & & $\begin{array}{l}\mathrm{M}=2.35 \\
\mathrm{~F}=2.22\end{array}$ & $\begin{array}{l}\mathrm{M}=2.21 \\
\mathrm{~F}=2.17\end{array}$ & & $\begin{array}{l}\mathrm{M}=2.80 \\
\mathrm{~F}=3.43\end{array}$ & $\begin{array}{l}\mathrm{M}=3.01 \\
\mathrm{~F}=3.48\end{array}$ \\
\hline $\begin{array}{l}\text { Jodkowska et } \\
\text { al., } 2015\end{array}$ & $\begin{array}{l}\mathrm{n}=2300 \\
13-16 \text { years }\end{array}$ & $\begin{array}{c}M=1041 \\
F=1259\end{array}$ & 21-Question Questionnaire & $\begin{array}{l}\mathrm{M}=31.7 \% \\
\mathrm{~F}=50.5 \%\end{array}$ & $\begin{array}{l}\mathrm{M}=36.8 \% \\
\mathrm{~F}=45.7 \%\end{array}$ & & & $\begin{array}{l}\mathrm{M}=35.9 \% \\
\mathrm{~F}=55.4 \%\end{array}$ & & & & \\
\hline Dias et al., 2015 & $\begin{array}{c}\mathrm{n}=1409 \\
14-19 \text { years }\end{array}$ & $\begin{array}{l}M=636 \\
F=773\end{array}$ & 12-Question Questionnaire & $\begin{array}{l}\mathrm{M}=43.7 \% \\
\mathrm{~F}=48.8 \%\end{array}$ & $\begin{array}{l}\mathrm{M}=58.7 \% \\
\mathrm{~F}=75.8 \%\end{array}$ & $\begin{array}{l}\mathrm{M}=25.1 \% \\
\mathrm{~F}=40.5 \%\end{array}$ & & $\begin{aligned} \mathrm{M} & =25.8 \% \\
\mathrm{~F} & =53.2\end{aligned}$ & $\begin{aligned} M & =33.5 \% \\
F & =45.0\end{aligned}$ & & $\begin{array}{l}\mathrm{M}=39.8 \% \\
\mathrm{~F}=51.2 \%\end{array}$ & $\begin{aligned} M & =35.8 \% \\
\mathrm{~F} & =64.1\end{aligned}$ \\
\hline $\begin{array}{l}\text { Stanish et al., } \\
2015\end{array}$ & $\begin{array}{c}\mathrm{n}=60 \\
13-18 \text { years }\end{array}$ & $\begin{array}{l}\mathrm{M}=36 \\
\mathrm{~F}=24\end{array}$ & $\begin{array}{l}\text { 12-Question } \\
\text { Questionnaire }\end{array}$ & $55.0 \%$ & $6.7 \%$ & & $33.3 \%$ & & $8.3 \%$ & $25 \%$ & & $41.7 \%$ \\
\hline $\begin{array}{l}\text { Fernández et al., } \\
2016\end{array}$ & $\begin{array}{c}\mathrm{n}=143 \\
\text { Average } 15 \\
\text { years }\end{array}$ & $\begin{array}{l}M=77 \\
\mathrm{~F}=66\end{array}$ & $\begin{array}{l}\text { 17-Question Questionnaire, related to } 4 \\
\text { barriers }(0-10)\end{array}$ & $\begin{array}{l}\mathrm{M}=2.7 \\
\mathrm{~F}=3.3\end{array}$ & & & & $\begin{array}{l}\mathrm{M}=1.9 \\
\mathrm{~F}=2.9\end{array}$ & $\begin{array}{l}\mathrm{M}=1.6 \\
\mathrm{~F}=1.3\end{array}$ & $\begin{array}{l}\mathrm{M}=1.2 \\
\mathrm{~F}=2.6\end{array}$ & & \\
\hline $\begin{array}{l}\text { Rosselli et al., } \\
2020\end{array}$ & $\begin{array}{c}\mathrm{n}=368 \\
18.3 \pm 0.7 \\
\text { years }\end{array}$ & $\begin{array}{l}M=216 \\
F=152\end{array}$ & $\begin{array}{l}\text { 21-questionnaire, } 3 \text { questions for each } \\
\text { barrier (score } 0-9 \text { ) }\end{array}$ & $\begin{aligned} \mathrm{M} & =2.0 \\
\mathrm{~F} & =3.4\end{aligned}$ & $\begin{aligned} \mathrm{M} & =1.5 \\
\mathrm{~F} & =2.2\end{aligned}$ & $\begin{aligned} \mathrm{M} & =1.9 \\
\mathrm{~F} & =3.2\end{aligned}$ & $\begin{array}{c}\mathrm{M}=0.8 \\
\mathrm{~F}=0.6\end{array}$ & $\begin{array}{c}\mathrm{M}=2.2 \\
\mathrm{~F}=3.8\end{array}$ & $\begin{array}{l}\mathrm{M}=1.4 \\
\mathrm{~F}=1.5\end{array}$ & & & \\
\hline
\end{tabular}

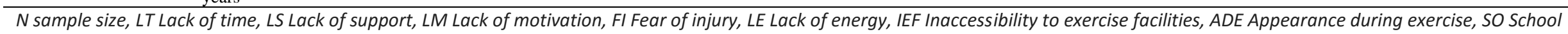

obligations, OA Other activities. 


\section{Inaccessibility to Exercise Facilities}

Butt et al. (2011) achieved an average score of 15.1 in boys and 16.2 in girls on a scale of 6-30, while in the study of Fernández et al., 2016, the barrier of inaccessibility of the facility had the lowest score of 1.5.

\section{Appearance during Exercise}

In the study by Robbins et al. (2003), the mean score was $2.80,57 \%$ of adolescents answered that they were aware of their appearance during exercises, as in the study by Fernández et al., 2016 with an average score of 2.5 in adolescents and 1.2 in adolescents. in the study of Arzu et al. (2006) and in adolescents a slightly lower average grade (3.56 and 4.24).

\section{School Obligations}

In the studies of Arzu et al. (2006) and Youssef et al. (2013) as the highest observed value in the question that indicated lack of time due to school obligations, ie $65.4 \%$ In the study of Robbins et al. (2003) 54.6\% of adolescents said that school obligations prohibited engaging in physical activity, while the average grade is 2.42 .

\section{Other Activities}

In a study by Youssef et al. (2013), as many as $72.2 \%$ of respondents agreed that other activities were more fun than engaging in physical activity.

\section{Discussion}

Most studies have shown that more internal barriers than external ones occur in girls more than in boys, while external barriers are a more common cause of not engaging in physical activity in boys (Arzu et al., 2006; Stanish et al., 2015; Fernández et al., 2016). The three most common barriers among boys were: lack of company, lack of time and school obligations. Among girls, the most commonly reported barriers were "I would rather do some other activities" and lack of time (Dias et al., 2015). Barriers that make it impossible to play sports are not significant to a large extent because the respondents will always find a reason not to engage in sports activity from a subjective point of view.
Subjectively perceived barriers are not adequate indicators of why a child is not able to engage in a certain sports activity. These are just the reasons they find in order to justify not being involved in sports activities, and it follows that the only reason and the biggest subjectively perceived barrier is laziness and mental unwillingness of the child to start engaging in physical activity. According to Serra-Paya, (2015), watching television in free time is statistically significantly negatively associated with engaging in physical activity, which means that children who watch more television, they do exercises less and vice versa. More than 50\% (score greater than 2.50) of girls gave a high score on barriers to physical activity (Robbins et al., 2003). Study Lovel et al. (2010) based on the assessments, it showed that a small number of adolescents consider the lack of support as a barrier to physical activity as well as answers to the question "It is too uncomfortable for me, in order to exercise", while most agree that inaccessibility to facilities and lack of energy are barriers. The most common barriers to physical activity were a lack of time, a lack of support, and a lack of energy. Significant differences between boys and girls occurred in a study by Fernández et al. (2016) related to the lack of energy barrier along with awareness of their appearance during exercise as well as in a study by Jodkowska et al. (2015) ( $\mathrm{F}=55.4 \%$; $\mathrm{M}$ $=35,9 \%$ ). The difference between the sexes did not occur in the barriers lack of time and inaccessibility to facilities in the study by Fernández et al. (2016) while in the Joowe study the difference between girls and boys was $28.8 \%$. Most studies have come to the same conclusion; that boys are more physically active than girls and that they have significantly fewer barriers than girls. A larger number of external barriers, than internal ones, was the reason for not engaging in physical activity.The four highest-ranked excuse reasons were, "I don't have free time to exercise because of school obligations," "My parents prefer school obligations tosports.", "I don't have time for other things that I am interested in," and "I never have enough energy for all obligations". Excuse - reasons Items related to internal barriers have a low rankingrate. Only one reason, which indicated a lack of energy, reached a significant level. This was shown by studies that dealt with internal barriers. Internal barriers are just as important as external ones in young people (Giurcsik et al., 2004; Allison et al., 2005). Physical activity has a great impact on physical and mental health. In children and adolescents, physical activity can: improve bone health, improve cardiorespiratory and muscular shape, reduce body fat 
levels, reduce symptoms of depression.Nevertheless, the number of adolescents who have daily physical activity is decreasing. Personal, social, economic and environmental factors play a significant role in the degree of physical activity in which young, adults and the elderly participate. It is important to understand the barriers and factors that stimulate physical activity in order to ensure the effectiveness of various programs aimed at improving the level of physical activity of the population. However, a large number of girls and adolescents often have a problem with their physical appearance, so finding them wearing sports clothes during physical education classes causes them discomfort. Also, girls do not like to sweat, and most often their hairstyle and make-up stop them from being ready for physical activity. Adolescents should be motivated to develop new skills, teamwork skills, organization, leadership and a positive attitude towards body appearance. Families have a great influence on children's physical activity, but that influence decreases with the growth of children. Despite the fact that adolescents are far more influenced by their peers, the family can still contribute to creating a positive attitude towards physical activity. Parents can set a personal example (recreation, garden work, etc.), as well as by organizing joint physical activities. It is one of the barriers that most often occur among adolescents. Another barrier is the desire of adolescents to spend their free time engaging in activities other than exercise. With adequate organization of daily activities, 60 minutes can be set aside for engaging in some physical activity. Motivation is a very important factor. Adolescents should find a reason why they should exercise, whether it was "I want to look good", "I have to train to be healthy", "I want to persevere and succeed in this sport because of this and that." or motivation by parents, teachers, coaches, others in the environment. Support is also an important factor in avoiding barriers.

This research was limited to barriers related to adolescents. In addition to all the advantages of the study, the limitation of the study is that the results can only be applied to adolescents, barriers apply only to one group of people and to a sample of respondents that does not cover a slightly wider spectrum (recreational athletes). Future studies should extend these observations to other groups of respondents, groups related to respondents who play a sport or are recreational, to groups of respondents of different ages.

\section{Conclusion}

The significance of this research is that it provides information on barriers in respondents who are adolescents, ie the reasons why their physical activity is reduced or they do not engage in physical activity at all.

\section{References}

Allison, K. R., Dwyer, J. J., Goldenberg, E., Fein, A., Yoshida, K. K., \& Boutilier, M. (2005). Male adolescents' reasons for participating in physical activity, barriers to participation, and suggestions for increasing participation. Adolescence, 40(157).

Arzu, D., Tuzun, E. H., \& Eker, L. (2006). Perceived barriers to physical activity in university students. Journal of Sports Science \& Medicine, 5(4), 615.

Bauer, K. W., Yang, Y. W., \& Austin, S. B. (2004). "How can we stay healthy when you're throwing all of this in front of us?" Findings from focus groups and interviews in middle schools on environmental influences on nutrition and physical activity. Health Education \& Behavior, 31(1), 3446.

Brown, S. A. (2005) Measuring perceived benefits and perceived barriers for physical activity. American Journal of Health Behavior, 29(2), 107-116.

Buckworth, J., \& Dishman, R. K. (1999). Determinants of physical activity: research to application. Lifestyle Medicine, 1016-1027.

Butt, J., Weinberg, R. S., Breckon, J. D., \& Claytor, R. P. (2011). Adolescent physical activity participation and motivational determinants across gender, age, and race. Journal of Physical Activity and Health, 8(8), 10741083.

Cheng, K. Y., Cheng, P. G., Mak, K. T., Wong, S. H., Wong, Y. K. \& Yeung, E. W. (2003). Relationships of perceived benefits and barriers to physical activity, physical activity participation and physical fitness in Hong Kong female adolescents. Journal of Sports Medicine Physical Fitness $43,523-529$.

Cohen, D. A., Ashwood, J. S., Scott, M. M., Overton, A., Evenson, K. R., Staten, L. K., Porter, D., McKenzie, D. L., \& Catellier, D. (2006). Public parks and physical activity among adolescent girls. Pediatrics, 118(5), e1381-e1389.

Dias, D. F., Loch, M. R., \& Ronque, E. R. V. (2015). Perceived barriers to leisure-time physical activity and associated factors in adolescents. Ciencia \& saudecoletiva, 20, 33393350 . 
Eccles, J. S., Midgley, C., Wigfield, A., Buchanan, C. M., Reuman, D., Flanagan, C., \& Mac Iver, D. (1993). Development during adolescence: The impact of stage-environment fit on young adolescents' experiences in schools and in families. American Psychologist, 48(2), 90-101.

Escat, Generalitat de Catalunya. (2013) Catalunya 2012 Informe dels principals resultats. Enq Salut Catalunya [Internet]. 1a :1-64.

Fernández, I., Canet, O., \& Giné-Garriga, M. (2017). Assessment of physical activity levels, fitness and perceived barriers to physical activity practice in adolescents: cross-sectional study. European Journal of Pediatrics, 176(1), 57-65.

García Gómez, M., Urbanos Garrido, R., Castañeda López, R., \& López Menduiña, P. (2012). Costes sanitarios directos de las neoplasias de pulmón y vejiga de origenlaboral en España en 2008. Revista Española de SaludPública, 86(2), 127-138.

Goh, Y. Y., Bogart, L. M., Sipple-Asher, B. K., Uyeda, K., HawesDawson, J., Olarita-Dhungana, J., Ryan, G. W., \& Schuster, M. A. (2009). Using community-based participatory research to identify potential interventions to overcome barriers to adolescents' healthy eating and physical activity. Journal of behavioral medicine, 32(5), 491-502.

Gordon-Larsen, P., Griffiths, P., Bentley, M. E., Ward, D. S., Kelsey, K., Sheilds, K., \& Ammerman, A. (2004). Barriers to physical activity: Qualitative data on caregiverdaughter perceptions and practices. American Journal of Preventive Medicine, 27(3), 218-223.

Grubbs, L., \& Carter, J. (2002) The relationship of perceived benefits and barriers to reported exercise behaviors. Family \& Community Health 25(2), 76- 84.

Gubbels, J. S., van Assema, P., \& Kremers, S. P. (2013). Physical activity, sedentary behavior, and dietary patterns among children. Current nutrition reports, 2(2), 105-112.

Gyurcsik, N. C., Bray, S. R., \& Brittain, D. R. (2004). Coping with barriers to vigorous physical activity during transition to university. Family \& Community Health, 27(2), 130-142.

Haugen, T., Ommundsen, Y., \& Seiler, S. (2013). The relationship between physical activity and physical selfesteem in adolescents: The role of physical fitness indices. Pediatric exercise science, 25(1), 138-153.

Hesketh, K., Waters, E., Green, J., Salmon, L., \& Williams, J. (2005). Healthy eating, activity and obesity prevention: A qualitative study of parent and child perceptions in Australia. Health Promotion International, 20(1), 19-26.

Hohepa, M., Schofield, G., \& Kolt, G. S. (2006). Physical activity: what do high school students think?. Journal of Adolescent Health, 39(3), 328-336.
Janssen, I., Boyce, W. F., Simpson, K., \& Pickett, W. (2006). Influence of individual-and area-level measures of socioeconomic status on obesity, unhealthy eating, and physical inactivity in Canadian adolescents. The American journal of clinical nutrition, 83(1), 139-145.

Jodkowska, M., Mazur, J., \& Oblacińska, A. (2015). Perceived barriers to physical activity among Polish adolescents. Przegl Epidemiol, 69(1), 73-78.

Kann, L., Kinchen, S.A., Williams, B.I., Ross, J.G., Lowry, R., Grunbaum, J.A. \& Kolbe, L.J. (2000). Youth risk behavior surveillance: United States, 1999. Morbidity and mortality weekly report. CDC surveillance summaries / Centers for Disease Control, 49(5), 1-32.

Kenneth, R.A., Dwyer, J.M. \& Makin, S. (1999) Perceived barriers to physical activity among high school students. Preventive Medicine 28, 608-615.

Kleinert, S. (2007). Adolescent health: an opportunity not to be missed. The Lancet, 9567(369), 1057-1058.

Kubik, M. Y., Lytle, L. A., \& Fulkerson, J. A. (2005). Fruits, vegetables, and football: Findings from focus groups with alternative high school students regarding eating and physical activity. Journal of Adolescent Health, 36(6), 494500 .

Kvaavik, E., Klepp, K. I., Tell, G. S., Meyer, H. E., \& Batty, G. D. (2009). Physical fitness and physical activity at age 13 years as predictors of cardiovascular disease risk factors at ages 15, 25, 33, and 40 years: extended follow-up of the Oslo Youth Study. Pediatrics, 123(1), e80-e86.

Kwan, M. Y., Cairney, J., Faulkner, G. E., \& Pullenayegum, E. E. (2012). Physical activity and other health-risk behaviors during the transition into early adulthood: a longitudinal cohort study.American journal of preventive medicine, 42(1), 14-20.

Lovell, G. P., El Ansari, W., \& Parker, J. K. (2010). Perceived exercise benefits and barriers of non-exercising female university students in the United Kingdom. International Journal of Environmental Research and Public Health, 7(3), 784-798.

Moher, D., Liberati, A., Tetzlaff, J., Altman, D. G., \& Prisma Group. (2009). Preferred reporting items for systematic reviews and meta-analyses: the PRISMA statement. PLoS med, 6(7), e1000097.

Niñerola, J., Ortis, L. C. \& Pintanel, M. (2006). Barreras percibidas y actividad física: El autoinforme de barreras para la práctica de ejercicio físico. Revista de Psicologia del Deporte, 15(1): 53-69.

Organization WH. (2010) Recomendaciones Mundialessobre Actividad Física para la Salud. Geneva WHO Libr Cat [Internet]. (Completo):1-58.

Ortega, F. B., Ruiz, J. R., \& Castillo, M. J. (2013). Physical activity, physical fitness, and overweight in children and 
adolescents: evidence from epidemiologic studies. Endocrinología y Nutrición (English Edition), 60(8), 458-469.

Rennie, K. L., Johnson, L., \& Jebb, S. A. (2005). Behavioural determinants of obesity. Best Practice \& Research Clinical Endocrinology \& Metabolism, 19(3), 343-358.

Robbins, L. B., Pender, N. J., \& Kazanis, A. S. (2003). Barriers to physical activityperceived by adolescent girls. Journal of Midwifery \& Women's Health, 48(3), 206-212.

Rodenburg, G., Oenema, A., Pasma, M., Kremers, S. P., \& van de Mheen, D. (2013). Clustering of food and activity preferences in primary school children. Appetite, 60, 123132.

Rosselli, M., Ermini, E., Tosi, B., Boddi, M., Stefani, L., Toncelli, L., \& Modesti, P. A. (2020). Gender Differences In Barriers To Physical Activity Among Adolescents. Nutrition, Metabolism and Cardiovascular Diseases.

Sherar, L. B., Gyurcsik, N. C., Humbert, M. L., Dyck, R. F., Fowler-Kerry, S., \& Baxter-Jones, A. D. (2009). Activity and barriers in girls (8-16 yr) based on grade and maturity status. Medicine \& Science in Sports \& Exercise, 41(1), 87-95.

Serra-Paya, N. (2015). Physical Activity Behavior, Aerobic Fitness and Quality od Life in School-Age Children. Procedia - Social and Behavioral Sciences, 191, 17581762.

Sigmundová, D., Chmelík, F., Sigmund, E., Feltlová, D., \& Frömel, K. (2013). Physical activity in the lifestyle of Czech university students: Meeting health recommendations. European Journal of Sport Science, 13(6), 744-750.

Singh, A. S., Mulder, C., Twisk, J. W. R., Van Mechelen, W., \& Chinapaw, M. J. M. (2008) Tracking of childhood overweight into adulthood: a systematic review of the literature. Obesity Reviews. 474-88.

Stankov, I., Olds, T., \& Cargo, M. (2012). Overweight and obese adolescents: what turns them off physical activity?. International Journal of Behavioral Nutrition and Physical Activity, 9(1), 1-15.

Stanish, H., Curtin, C., Must, A., Phillips, S., Maslin, M., \& Bandini, L. (2015). Enjoyment, barriers, and beliefs about physical activity in adolescents with and without autism spectrum disorder.Adapted Physical Activity Quarterly, 32(4), 302-317.

Trost, S. G., Owen, N., Bauman, A. E., Sallis, J. F., \& Brown, W. (2002). Correlates of adults' participation in physical activity: review and update. Medicine \& science in sports \& exercise, 34(12), 1996-2001.

UNFPA. (2006). The state of the world population, 2003. Making one billion count: investing in adolescents' health rights. New York: UNFPA.

Winters, E. R., Petosa, R. L. \& Charlton, T. E. (2003) Using cognitive theory to explain discretionary, "leisure time" physical exercise among high school students. Journal of Adolescent Health 32, 436-42.

Youssef, R. M., Al Shafie, K., Al-Mukhaini, M., \& Al-Balushi, H. (2013). Physical activity and perceived barriers among high-school students in Muscat, Oman. Eastern Mediterranean Health Journal, 19(9). 